\title{
Электроэнергетика: экономические оттенки российских трендов ${ }^{1}$
}

E.В. ЛюБимовА, кандидат экономических наук, Институт экономики и организации промышленного производства СО РАН, Новосибирск. E-mail: kat@ieie.nsc.ru

Аннотация. Электроэнергетика - базовая отрасль промышленности, в которой за советский период была создана и настолько успешно функционировала Единая энергетическая система, что её характеристики до сих пор используются в качестве базы для оценки результатов энергореформ. Является сегодняшняя энергетика фактором или тормозом экономического развития России? Нуждается ли она в дальнейшем реформировании, и если да - то в каком и как именно? Ответы на эти вопросы должны быть даны в результате комплексной экспертизы, всестороннего их рассмотрения в профессиональных и научных кругах. В статье исследуются общеэкономические аспекты хозяйствования централизованной энергетики РФ, даются анализ статистических данных, выявление количественных и качественных тенденций их изменения, позволяющие оценить текущее состояние отрасли, её взаимоотношения с потребителями.

Ключевые слова: электроэнергия; Единая энергосистема России; экономика; реформа; тариф; эффективность; управление

Электроэнергетика - одна из базовых отраслей национальной экономики, ее доля в промышленном производстве страны, оцененная по объему ВВП, колеблется в последние годы около $10 \%$. Региональное размещение генерирующих мощностей неравномерно, и вклад отрасли в производство различных регионов страны варьируется от $1 \%$ до 50\% ВРП. При этом в половине субъектов Федерации доля энергетики близка к среднероссийской, в пятой части регионов - не превышает 10\%, примерно в $1 / 3$ составляет от $20 \%$ до $30 \%$, а в 10 регионах превышает $30 \%$ промышленного производства.

Повышенный удельный вес энергетики в структуре экономики того или иного региона вовсе не означает её реальной значимости в масштабе всей страны, тем более что доля отрасли подсчитывается в стоимостном выражении, и тут разница в тарифах может сыграть не меньшую роль, чем разница в величине

\footnotetext{
${ }^{1}$ Статья подготовлена по плану НИР ИЭОПП СО РАН в рамках приоритетного направления XI.172, проект XI.172.1.1 (0325-2019-0010).
} 
установленных мощностей. К примеру, Корякский автономный округ, будучи еще субъектом Федерации, значился по показателю удельного веса энергетики в группе «сильных» вместе с Тюменской областью и г. Москва, промышленная и энергетическая мощь которых в 50-300 раз больше, чем у округа. Существенная доля энергетики в региональном производстве при сильной промышленности положительно характеризует экономический потенциал субъекта, при слабой промышленности - это отражение диспропорциональности региональной экономики.

Основные характеристики размещения генерирующих мощностей по макрозонам страны заложены ещё в советский период и исключительно устойчивы. И сегодня на северо-западе европейской части России заметная доля генерирующих мощностей сосредоточена на АЭС, в большинстве остальных её районов и на Урале доминируют газовые ТЭС, в Сибири преобладают ГЭС, а тепловые станции работают на угле (кроме Тюменской области и Ханты-Мансийского АО), а на Дальнем Востоке большая часть электро- и теплоэнергии производится на угольных ТЭС. В европейской части создана развитая сетевая структура, обслуживающая большое количество рассредоточенных потребителей. В восточных районах, напротив, основные объемы потребления сконцентрированы в крупных узлах, расположенных на больших расстояниях друг от друга.

Динамика и структура потребления электроэнергии (табл. 1) главным образом отражают достигнутый размах и динамику хозяйственной деятельность макрорегионов. Три четверти произведенной электроэнергии устойчиво потребляется в четырёх из восьми федеральных округов - Центральном, Сибирском, Приволжском, Уральском (в порядке убывания). При этом благодаря наличию единой энергосистемы, обеспечивающей межрегиональные перетоки, степень избыточности или дефицитности каждого конкретного региона по электроэнергии не имеет сильного воздействия на процессы функционирования и развития его экономики.

За четыре отчетных года электропотребление страны выросло на 4\%, что весьма обнадёживает, особенно в свете его рецессивного спада на 4,8 млрд кВт·ч в 2015 г. 
Таблица 1. Потребление электроэнергии по федеральным округам в 2014-2018 гг., млрд кВт-ч

\begin{tabular}{|l|c|c|c|}
\hline \multicolumn{1}{|c|}{ Федеральный округ } & $\mathbf{2 0 1 4}$ & $\mathbf{2 0 1 6}$ & $\mathbf{2 0 1 8}$ \\
\hline Российская Федерация & 1065,0 & 1078,4 & 1108,1 \\
\hline Центральный & 213,6 & 219,6 & 227,1 \\
\hline Северо-Западный & 109,7 & 111,8 & 114,6 \\
\hline Южный (+Крымский федеральный округ) & 70,3 & 69,4 & 73,6 \\
\hline Северо-Кавказский & 23,0 & 24,7 & 25,0 \\
\hline Приволжский & 197,4 & 197,5 & 204,0 \\
\hline Уральский & 182,3 & 184,5 & 188,6 \\
\hline Сибирский (СФО) & 223,2 & 221,8 & 210,0 \\
\hline Дальневосточный (ДФО) ${ }^{\star}$ & 45,5 & 49,1 & 65,3 \\
\hline СФО+ДФО & 268,7 & 270,9 & 275,3 \\
\hline
\end{tabular}

Источник: Росстат http://www.gks.ru/wps/wcm/connect/rosstat_main/rosstat/ru/ statistics/enterprise/industrial/

*Учитывается перемещение двух субъектов Федерации из СФО в ДФО в 2018 г.

Потребность в энергии определяет объем её генерации (с учетом экспортно-импортного сальдо), и в основном (на 96\%) удовлетворяется электростанциями, включёнными в Единую энергетическую систему (ЕЭС) России, охватывающую более 80\% территории страны. В районах, не охваченных централизованным электроснабжением, действуют изолированные энергосистемы и энергоузлы, а также отдельные электростанции и энергоустановки в отдалённых и малонаселённых местностях. Этот сегмент электроэнергетики имеет особенные характеристики и собственный круг проблем, не присущих «большой энергетике». Данная статья направлена на рассмотрение трендов, существующих в централизованном сегменте энергетической отрасли.

\section{Этапность перемен}

Согласно данным Системного оператора (CO) ЕЭС, Единая энергетическая система России состоит из 71 региональной энергосистемы, которые, в свою очередь, образуют семь объединенных энергетических систем: Востока, Сибири, Урала, Средней Волги, Юга, Центра и Северо-Запада. Все они соединены межсистемными высоковольтными линиями электропередачи напряжением 220-500 кВ и выше и работают в синхронном режиме (параллельно). На 1 января 2019 г. общая установленная мощность электростанций «ЕЭС России» составила 243,2 тыс. МВт. 
В 2018 г. 64\% их выработки обеспечили тепловые станции, $17 \%$ - гидравлические, $19 \%$ - атомные и менее $0,1 \%$ - станции на возобновляемых источниках энергии. Мощность свыше 5 MBт имеют 805 электростанций.

В постсоветский период национальная энергосистема дважды подвергалась кардинальному реформированию. В 1992 г. в энергетике начались акционирование и частичная приватизация с созданием отраслевого холдинга РАО «ЕЭС России», подконтрольных ему территориальных интегрированных энергетических компаний (АО-энерго, практически совпадающих с территориями соответствующих субъектов Федерации) и выделенных из состава последних крупных электростанций. В нескольких субъектах Федерации не удалось создать подконтрольные холдингу АО-энерго, и их энергетику стали представлять независимые региональные энергокомпании. Атомная энергетика была выделена в госконцерн «Росэнергоатом» и работала как производственная структура Минатома России. Было положено начало использованию в отрасли рыночных взаимоотношений - образованы Федеральный оптовый рынок электроэнергии (мощности) - ФОРЭМ и розничные рынки электроэнергии в рамках зон деятельности каждой из АО-энерго (субъекта Федерации).

Этот период совпал с чрезвычайно тяжелым для постсоветской экономики временем гиперинфляции, спадом промышленного электропотребления практически вдвое, кризисом неплатежей, отсутствием не только инвестиционных ресурсов, но и оборотных средств. Российской энергетике хватило советского запаса прочности, чтобы выжить в этой ситуации.

В ходе второго этапа реформирования отрасли произошла её дальнейшая «атомизация». В 2008 г. РАО «ЕЭС России» прекратило своё существование, разделившись на новые компании электроэнергетики. В европейской части страны и в Сибири подконтрольные холдингу предприятия были обособлены по видам деятельности - производство, передача, распределение, сбыт электроэнергии. На Дальнем Востоке такого обособления не произошло из-за технической изолированности его энергосистем, которые вошли в состав холдинга РАО «Энергетические системы Востока» (в 2017 г. его материнской компанией стало «РусГидро»). «Интер РАО ЕЭС», дочернее предприятие 
PАО «ЕЭС России», стало независимым без изменений в активах. Обслуживающие, ремонтные, проектные, научные и другие подразделения и организации неэнергетического характера выведены из состава предприятий энергетики.

В сфере производства были созданы оптовые генерирующие компании (ОГК), работающие только на оптовый рынок электроэнергии, и территориальные (ТГК), производящие энергию только для потребителей подконтрольной им территории. Почти все ГЭС РАО «ЕЭС России» вошли в состав отдельного ГидроОГК (ныне «РусГидро»). АЭС, как и прежде, находятся под управлением «Росэнергоатома». Несколько региональных энергокомпаний, обособившихся в период первого реформирования, сохранили свою независимость.

В тепловые ОГК вошло подавляющее большинство крупных ТЭС, причём набор каждой из них формировался из станций разных макрорегионов. В целом, состав ОГК насчитывал около трети генерирующих мощностей страны. В дальнейшем ОГК сливались, переименовывались и на данный момент существует шесть агентов оптового рынка энергии: «ОГК-2», «Интер РАО», «Юнипро», «Энел Россия», «РусГидро» и «Росэнергоатом».

ТГК формировались на основе одного или нескольких АОэнерго, из которых исключались гидростанции (объединены в «РусГидро») и крупные ТЭС (объединены в ОГК). На их долю в совокупности приходится около четверти всех установленных мощностей страны и около трети тепловой генерации. Впоследствии эти компании также переименовывались, сливались ${ }^{2}$, и только пять из «доживших» до настоящего времени одиннадцати сохранили в названии первоначальную аббревиатуру: «ТГК-1», «ТГК-2», «Мосэнерго», «Квадра», «Т Плюс», «Лукойл-Экоэнерго», «Фортум», «ТГК-11», «Кузбассэнерго», «Енисейская ТГК» («ТГК-13»), «ТГК-14».

В сетевом хозяйстве создана следующая градация. Магистральные линии электропередач находятся под управлением

\footnotetext{
${ }^{2}$ Например, «Кузбассэнерго» («ТГК-12»), «Енисейская ТГК» («ТГК-13») вместе с другими генерирующими активами вошли в состав энергетического холдинга «Сибирская генерирующая компания», созданного в 2009 г. и сегодня осуществляющим свою деятельность на территории 6 субъектов Федерации СФО, выдавая 23-25\% от выработки тепла и электроэнергии энергосистемы Сибири.
} 
Федеральной сетевой компании «ФСК ЕЭС», у которой девять филиалов - МЭС (Магистральные электрические сети), каждый из которых включает в себя 4-8 предприятий. Основа структуры распределения электроэнергии - межрегиональные распределительные сетевые компании (МРСК), в которые входят распределительные сетевые компании (РСК), «унаследовавшие» сетевые активы реорганизованных АО-энерго. В настоящее время и МРСК и ФСК объединены под эгидой ОАО «Россети» (владеет и управляет).

Предприятия электроэнергетики, осуществляющие монопольные виды деятельности (передача, распределение, диспетчирование), часть стратегически важных генерирующих активов (гидро- и атомная энергетика), «РАО Энергетические системы Востока» и «Интер РАО ЕЭС» остались в государственной собственности. Реструктурированные генерирующие компании были приватизированы. Новые владельцы - крупные российские госкорпорации (например, «Газпром» и РЖД), зарубежные (Е.ON, Fortum, Enel), офшорные компании, российские физические лица. Перераспределение собственности в отрасли происходит до сих пор [Шевелёва, 2017].

Новые субъекты электроэнергетики переведены на рыночные механизмы во всех сферах их деятельности. При этом сохранена и продолжает развиваться двухуровневая система организации рынков электроэнергии:

- функционирование и развитие оптовых рынков электроэнергии и мощности (ОРЭМ) в двух ценовых зонах осуществляются в форме рынка свободных договоров, рынка на сутки вперёд, балансирующего рынка, рынка мощности. В неценовых зонах продажа энергии происходит по регулируемым тарифам;

- на розничных рынках, как и прежде ограниченных территорией «своего» субъекта Федерации, энергоснабжающие организации продают электроэнергию потребителям. Населению и приравненным к нему категориям - по фиксированным (регулируемым) тарифам, остальным - по свободным ценам. Продажа электроэнергии осуществляется по одной из шести ценовых категорий, право выбора которой предоставлено самим потребителям - исходя из максимальной мощности используемого оборудования и способах планирования собственного потребления и оплаты услуг по передаче. 
Последнее пятилетие по «ЕЭС России» в целом наблюдается устойчивый рост выработки электроэнергии (табл. 2). Небольшое падение потребления в 2015 г. - одно из проявлений экономической рецессии, восстановление после которой началось уже в 2016 г.

\section{Таблица 2. Характеристики деятельности «ЕЭС России» в 2014-2018 гr.}

\begin{tabular}{|l|c|c|c|c|c|}
\hline \multicolumn{1}{|c|}{ Показатель } & $\mathbf{2 0 1 4}$ & $\mathbf{2 0 1 5}$ & $\mathbf{2 0 1 6}$ & $\mathbf{2 0 1 7}$ & $\mathbf{2 0 1 8}$ \\
\hline Производство электроэнергии, млрд кВт·4 & & & & & \\
\hline «ЕЭС России» & 1024,8 & 1026,9 & 1048,6 & 1053,9 & 1070,9 \\
\hline Всего по РФ & 1064,2 & 1067,5 & 1091,1 & 1094,3 & 1115,1 \\
\hline Потребление электроэнергии, млрд кВт·ч & & & & & \\
\hline «ЕЭС России» & 1013,8 & 1008,3 & 1026,8 & 1039,9 & 1055,6 \\
\hline Всего по РФ & 1065,0 & 1060,2 & 1077,9 & 1089,1 & 1108,1 \\
\hline $\begin{array}{l}\text { Ввод новых мощностей «ЕЭС России» (без учета } \\
\text { модернизации), тыс. МВт }\end{array}$ & 7,3 & 4,7 & 4,2 & 3,6 & 4,5 \\
\hline
\end{tabular}

Источник: «CO EЭC». URL: https://www.so-ups.ru/index.php?id=tech_disc; Росстат http://www.gks.ru/wps/wcm/connect/rosstat_main/rosstat/ru/statistics/ enterprise/industrial/

Незначительный рост выработки электроэнергии (в среднем менее $1 \%$ ежегодно в последнюю пятилетку) практически не сказался на степени загрузки мощностей (табл. 3). У ТЭС загрузка даже уменьшилась. Это связано с тем, что они являются балансирующими и таким образом реагируют на увеличение загрузки других типов станций. Отметим, что в таблице отражены среднегодовые показатели, однако потребление и, соответственно, тепловая генерация энергии намного больше в зимний период, когда на ГЭС выработка минимальна. По данным «СО ЕЭС» ${ }^{3}$, как правило, АЭС загружены зимой на 92-96\%, летом - на 0,650,70\%, ТЭС летом разгружаются примерно до $40 \%$ установленной мощности, а зимой догружаются до 60-65\%. Таким образом, реальный резерв атомных станций минимален, а по тепловым он меньше посчитанного по среднегодовому показателю (при этом нужно учитывать еще требование обязательного резервирования). С учётом всех этих соображений резерв мощностей действующих тепловых станций составляет в среднем около $20 \%$ (отличается по регионам).

\footnotetext{
${ }^{3}$ URL: https://www.so-ups.ru/index.php?id=ups_review
} 
Таблица 3. Коэффициенты загрузки мощностей станций “ЕЭС России" в 2012 г., 2013 г., 2018 г., \%

\begin{tabular}{|l|l|l|l|}
\hline \multicolumn{1}{|c|}{ Год } & \multicolumn{1}{c|}{ тЭС } & \multicolumn{1}{c|}{ гЭС } & \multicolumn{1}{c|}{ АЭС } \\
\hline $2012-2013$ & $52,4-49,9$ & $39,5-43,1$ & $72,4-77,9$ \\
\hline 2018 & 46,5 & 43,3 & 78,4 \\
\hline
\end{tabular}

Источник: «COEЭC».URL: https://www.so-ups.ru/index.php?id=ups_review; https:// www.so-ups.ru/index.php?id=tech_disc

\section{За что боролись...}

Оба этапа реформирования электроэнергетики обосновывались одним и тем же набором причин: неудовлетворённостью уровнем цен на энергию, отсутствием стимулов и источников воспроизводства производственного аппарата отрасли, недостаточной эффективностью функционирования и управления отрасли.

«ЕЭС России» успешно справляется с задачей надёжного снабжения потребителей электроэнергией. Тем не менее существует ряд негативных тенденций, в основной своей массе связываемые с недостаточно продуманными мерами реформирования и теоретическими просчётами.

Так, по мнению ряда экспертов, перенесение на российскую почву американской модели рынка РЈМ (объединение электросетей штатов: Пенсильвания, Нью-Джерси, Мэриленд, Делавер, Вирджиния и Огайо) было осуществлено без учёта характеристик отечественной энергетики [Кутовой, 2014]. В США эта модель работает в отсутствие сетевых ограничений и комбинированного производства тепло- и электроэнергии. В России способ вывода ТЭЦ на рынок (без учета специфики их работы, связанной с теплоснабжением) создал им большие экономические трудности [Паламарчук, Стенников, 2018], ставящие под сомнение целесообразность их существования. (Эта тема требует отдельного рассмотрения, невозможного в рамках короткой статьи.)

Серьёзные проблемы видятся в сетевом хозяйстве. Притом, что объём производства электроэнергии уже примерно равен дореформенному уровню, транспортные (сетевые) потери увеличились с 8,7\% в 1990 г. до 11,2\% к 2013 г. и с небольшими флуктуациями остаются сейчас на том же уровне. Такая динамика свидетельствует об отсутствии эффективного механизма мотивации снижения потерь. 
Не всё ладно с сетями и в другом аспекте. В результате выделения сетевого сектора в отдельную отрасль и его организационного дробления в ходе реформы, доля транспорта в цене конечного потребления электроэнергии резко выросла. В последнее десятилетие она колеблется вокруг $60 \%$ по РФ в целом [Суслов, Чёрная, 2016], что втрое превышает уровень 1990 г. Очевидно, что эта сфера содержит явный резерв снижения цен на электроэнергию, причем резерв именно организационного характера, поскольку именно организационное дробление сетевого сектора стран Западной Европы привело, по нашему мнению, к тому, что в этих странах доля затрат на передачу в структуре цены ещё выше, чем сейчас в России [Функционирование и развитие.., 2012].

Отмеченный выше большой резерв неиспользуемых мощностей тепловых станций теоретически мог бы рассматриваться как большой плюс единой энергосистемы России, если бы не их техническое состояние. Износ основных фондов энергетики в настоящее время почти дошёл до 50\%, а по машинам и оборудованию уже пересёк эту границу ${ }^{4}$. Оборудование продолжает находиться в эксплуатации, только нарастают риск аварий и ремонтные требования, что снижает и без того невысокую (по современным меркам) экономическую эффективность агрегатов (на уровне 40-50-летней давности, когда они были произведены). То же относится и к экологической составляющей.

При реформировании отрасли, как и всей экономики, предполагалось, что смена собственника поможет решить проблему её модернизации, что появившиеся в результате приватизации новые хозяева смогут и захотят (видимо, по мнению реформаторов, им больше ничего не останется) решить проблему обновления производственных фондов, с которой не справилось государство, получившее в наследство от СССР ещё не совсем старую (средний возраст энергетического оборудования к 1991 г. составлял 18 лет) и эффективно функционирующую энергосистему.

Практика показала беспочвенность такого ожидания. После практически «пустых» 1990-х за первое десятилетие XXI века суммарный ввод новых генерирующих мощностей

\footnotetext{
${ }^{4}$ Росстат. URL: http://www.gks.ru/wps/wcm/connect/rosstat_main/rosstat/ru/statistics / enterprise/fund/\#
} 
составил 8,5 тыс МВт. Для сравнения: в последнюю советскую пятилетку 1985-1990 гг. была введена 21 тыс. МВт. Таким образом получили наглядное подтверждение того, что пресловутые рыночные механизмы не содержат в своём составе стимулов развития и, тем более, стимулов координации развития энергетических систем в интересах общества.

С целью привлечения инвестиций в энергетику государство начало предоставлять гарантии возврата вложенных средств через договоры о предоставлении мощности (ДПМ), переложив тем самым на потребителей обязанность возврата средств, а вместе с ней и все экономические риски, связанные с реализацией поддержанных государством энергетических проектов. Механизм заработал, ввод новых мощностей перестал быть мизерным (табл. 2), и с 2008 г. на долю ДПМ в нём приходится более половины. Тем не менее претензии к инвестиционному механизму ДПМ до сих пор предъявляются и обсуждаются [Анализ развития.., 2013; Макаров И.Н., Макаров О.А. 2015; Чёрная, 2018]. Мы же лишь отметим, что это довольно странный механизм, при котором средства, взимаемые с потребителей на строительство новых предприятий, не обращаются в их собственность, не приносят дохода, а просто принудительно взимаются как некий налог. Точно такой же приём государство использует в ценовом механизме перекрестного субсидирования населения за счёт промышленных потребителей.

Все реформы энергетики проводились под знаменем мер по снижению тарифов на электроэнергию, чего потребители до сих пор не дождались. Более того - российские тарифы давно переросли мировой уровень. К 2010 г. в России по сравнению с США, ЕС и другими развитыми странами цена электроэнергии с учётом паритета покупательной способности была выше для промышленных потребителей в 1,5-5 раз, для населения - в 1-2 раза [Нигматулин, 2012]. И это при сохраняющемся (правда, постоянно снижающемся) перекрёстном субсидировании населения.

Остается и значительный региональный разброс энерготарифов, с позиций которого в России по-прежнему выделяются три зоны: европейская часть с Уралом, Сибирь и Дальний Восток. ДФО на общем фоне отличается более высокими тарифами для всех групп потребителей. Сибирь характеризуется чуть меньшими, чем в европейской части страны, тарифами и наибольшей 
региональной дифференциацией их уровня, тарифы европейской части страны и Урала более «гладкие».

Региональные различия в цене энергоресурсов обусловливают качественно разные условия для функционирования и развития региональных экономик, усиливают региональную дифференциацию, что вряд ли можно считать приемлемым в стране, исповедующей принципы федерализма и преодолевающей экономический кризис. Представляется, что, экономические механизмы рынков базовой и жизнеобеспечивающей отрасли должны все же способствовать сглаживанию регионального неравенства.

Темпы перехода от рецессии к устойчивому развитию в значительной степени зависят от того, насколько быстро может восстановиться и реструктурироваться промышленное производство, которое служит опорой экономики и является источником нормальных заработков граждан. Думается, что настала пора освободить промышленность от бремени оплаты за потребление населения и за строительство новых объектов других собственников.

На наш взгляд, в ходе разработки мер в сфере ценового регулирования отрасли разумно ставить задачу не только по уменьшению тарифов, полной ликвидации перекрёстного субсидирования, но и по сглаживанию тарифов между потребителями различных регионов. Возможная мера для последнего - укрупнение зонирования розничных рынков электроэнергии.

За время реформ в энергетике при незначительном увеличении производственных мощностей произошел резкий рост численности административно-управленческого персонала. В 1991 г. в отрасли трудились 720 тыс. человек и выработка на одного работника составляла 1,5 млн кВт·ч, в 2005 г. - уже 913 тыс. человек, а выработка упала на треть и составила только 1 млн кВт·ч [Ковалёв и др., 2017]. Рост трудоёмкости продукции энергетики продолжается, в настоящее время численность персонала отрасли насчитывает более 1 млн человек. При этом представители отрасли отмечают падение квалификации как технического, так и управленческого персонала, дефицит «свежих» квалифицированных кадров, проблемы в их подготовке [Магид, Архипова, 2010; Ковалёв и др., 2017]. Свою лепту в негатив кадрового вопроса внесло реформирование проектных институтов: была ликвидирована функция генеральной проектной 
организации, заключающаяся в сопровождении объекта на всем периоде его функционирования, разрушена система отраслевой научно-технической экспертизы. Ряд ключевых организаций отрасли, лишившись статуса головных организаций по различным функциональным направлениям, утратили нарабатывавшийся десятилетиями потенциал по разработке научно-технической документации.

В результате реформирования энергетики возросла сложность управления созданной системы. С ликвидацией РАО «ЕЭС России» утрачен отраслевой центр единого координирования функционирования и развития отрасли в интересах общества. Созданные многочисленные сложноструктурированные подсистемы электроэнергетики в качестве основной хозяйственной мотивации имеют собственную прибыль, а не общественное благо, а их раздробленность ведёт к значительному росту транзакционных затрат.

\section{Заключение}

Ряд исследователей под впечатлением негативных результатов реформ, часть которых рассмотрена в статье, утверждают, что российская электроэнергетика превратилась в сдерживающий фактор развития отечественной экономики [Кутовой, 2014]. Повидимому, такого рода высказывания свидетельствуют о неравнодушном отношении к состоянию отрасли, боли за ошибки в реформировании, приведшие к целому спектру долговременных негативных последствий не только для предприятий электроэнергетики, но и для всего общества. Очевидно, единственный путь не повторять таких ошибок - это организация комплексной экспертизы, всестороннего рассмотрения предполагаемых мер в профессиональных и научных кругах.

Электроэнергия является основой нашей цивилизации, и потому электроэнергетика как отрасль никак не может быть тормозом развития, она, безусловно, служит его основой и требует самого внимательного и профессионального к себе отношения. Очевидно, что Минэнерго России, взявшее на себя функции центра отраслевых компетенций, ещё не обладает необходимым набором действенных механизмов эффективного управления отраслью и пока лишь активно нарабатывает управленческий опыт. 
Хотелось бы верить, что революций в энергетике больше не будет и существующие проблемы будут решены путём эволюционных преобразований. К ключевым проблемам большой энергетики относятся:

- отсутствие стимулов и источников аккумулирования средств инновационного развития у предприятий производственного сектора электроэнергетики;

- социальная нагрузка на промышленные предприятия через энерготарифы и договоры, искажение ценовых сигналов, неиспользуемые резервы снижения тарифов на электроэнергию;

- значительный объём и сложность нормативно-правовых актов, регламентирующих деятельность отрасли;

- снижение кадрового потенциала отрасли.

\section{Литература}

Анализ развития реформ электроэнергетики и предложений по росту её эффективности. Аналитический доклад. М.: ИПЕМ. 2013. 43 с.

Ковалёв Г.Ф., Крупенёв Д. С., Лебедева Л. М. Обеспечение электроэнергетической отрасли квалифицированными кадрами как важнейшая проблема энергетической безопасности России // Энергия: экономика, техника, экология. 2017. № 2. С. 90-98.

Кутовой Г.П. Некоторые итоги вестернизации отечественной электроэнергетики в постсоветский 20 - летний период. // Доклад на семинаре МШЭ МГУ «Экономика энергетики и окружающей среды». M,, 2014. URL: http://yadi. sk/d/htqp6H5tJhBmK (дата обращения: 01.07.2019).

Магид С.И., Архипова Е.Н. «Человеческий фактор» и обеспечение надежности и безопасности в электроэнергетике // Надежность и безопасность энергетики. 2010. № 3(10). С. 6-12.

Макаров И.Н., Макаров О.А. Эффективность рынка электроэнергетики как фактор экономического развития России // Российское предпринимательство. 2015. Т. 16. № 16. С. 2651-2662.

Нигматулин Б. И. О причинах роста тарифов на электроэнергию // Энергия: экономика, техника, экология. 2012. № 1. С. 2-7.

Паламарчук С.И., Стенников В.А. Состояние и перспективы развития рынка электроэнергии в России // Энергетик. 2018. № 6. С. 43-46.

Суслов Н.И., Черная Н.В. Анализ колебаний валового регионального продукта и электропотребления в 2005-2014 годах и возможные резервы снижения цен на электроэнергию // Мир экономики и управления. 2016. Т. 16, № 3. C. 5-14.

Функционирование и развитие электроэнергетики Российской Федерации в 2011 году. Информационно-аналитический доклад. Минэнерго РФ, АПБЭ, СО ЕЭС, ФСК ЕЭС. М., 2012. 384 с. 
Черная Н. В. Новые генерирующие мощности, модернизация ТЭС, строительство объектов ВИЭ и рост цен на электроэнергию // Экономика и управление. 2018. № 10. С. 61-67.

Шевелёва Г.И. Кто и как владеет генерирующими активами в российской электроэнергетике? //ЭКО. 2017. № 6. С. 102-114.

Статья поступила 20.08.2019.

Для цитирования: Любимова Е.В. Электроэнергетика: экономические оттенки российских трендов// ЭКО. 2019. № 9. С. 8-22. DOI: 10.30680/ECO01317652-2019-9-8-22.

\section{Summary}

Lyubimova, E. V. Cand. Sci. (Econ.), Institute of Economics and Industrial Engineering, SB RAS, Novosibirsk

\section{Electric Power Industry: Economic Nuances of Russian Trends}

Abstract. The electric power industry is the basic industry in which during the Soviet period the Unified Energy System was created and operated so successfully that its characteristics are still used as a basis for assessing the results of energy reforms. Is today's energy a factor or a brake on Russia's economic development? Does it need further reform, and if so - in which and how exactly? These questions should be answered as a result of a comprehensive examination, extensive analysis in professional and scientific circles. The article examines the general economic aspects of managing the centralized energy sector of the Russian Federation, analyzes statistical data, identifies quantitative and qualitative trends in their changes, which make it possible to assess the current state of the industry and its relationship with consumers.

Keywords: electricity; Unified energy system of Russia; economy; reform; tariff; efficiency; managemen

\section{References}

Analysis of the development of power industry reforms and proposals for increasing its efficiency. Analytical report. (2013).Moscow, IPEM. 43 p. (In Russ.).

Kovalev, G.F., Krupenev, D.S., Lebedeva, L.M. (2017). Provision of skilled staff for electric power industry as a major problem of russian energy security. Energiya: ekonomika, tekhnika, ekologiya. No. 2. Pp. 90-98. (In Russ.).

Kutovoj, G.P. (2014). Some results of the westernization of the domestic electric power industry in the post-Soviet 20-year period. Doklad na seminare MSHE $M G U$ "Ekonomika energetiki i okruzhayushchej sredy» Report at the Moscow State University ISE Seminar "Economics of Energy and Environment". Moscow. (In Russ.). Available at: http://yadi.sk/d/htqp6H5tJhBmK (accessed 01.07.2019).

Magid, S.I., Arkhipova, E.N. (2010). The Human Factor and Ensuring Safety and Reliability in the Electric Power Industry. Safety and Reliability of Power Industry. No. 3(10). Pp. 6-12. (In Russ.). 
Makarov, I.N., Makarov, O.A. (2015). The effectiveness of electricity market as a factor of economic development of Russia. Russian journal of entrepreneurship. Vol. 16, No. 16. Pp. 2651-2662. (In Russ.).

Nigmatulin, B.I. (2012). About the reasons for the increase in electricity tariffs. Energiya: ekonomika, tekhnika, ekologiya. No. 1. Pp. 2-7. (In Russ.).

Palamarchuk, S.I., Stennikov, V.A. (2018.) Status and Perspectives for Electricity Market Development in Russia. Energetik. No. 6. Pp. 43-46. (In Russ.).

Suslov, N.I., Chernaya, N.V. (2016). Analysis of Gross Regional Product fluctuations and electric power consumption in 2005-2014. Reserves for decreasing electric power prices. World of economics and management. No. 3. Pp. 5-14. (In Russ.).

Operation and development of the electric power industry of the Russian Federation in 2011. Information and analytical report. (2012). Ministry of energy RF, APBE, SO UES, FGS UES. Moscow, 384 p. (In Russ.).

Chernaya, N. V. (2018). New Generating Capacity, Modernization of Thermal Power Plants, Constructions of RES Objects and Rise in Electricity Prices. Economics and management. No. 10. Pp. 61-67. (In Russ.).

Sheveleva, G. I. (2017). Who Owns Generation Assets in Russia's Power Industry and How? ECO. No. 6. Pp. 102-114. (In Russ.).

For citation: Lyubimova, E.V. (2019). Electric Power Industry: Economic Nuances of Russian Trends. ECO. No. 9. Pp. 8-22. (In Russ.). DOI: 10.30680/ ECO0131-7652-2019-9-8-22. 